\title{
Safety and Activity of Metronomic Temozolomide in Second-Line Treatment of Advanced Neuroendocrine Neoplasms
}

\author{
Salvatore Tafuto ${ }^{1,2,+}$, Claudia von Arx ${ }^{1,2,3,+} \mathbb{C}$, Monica Capozzi ${ }^{1,2, *}$, Fabiana Tatangelo ${ }^{2,4} \mathbb{D}$, \\ Manuela Mura 2,3, Roberta Modica 2,5 , Maria Luisa Barretta ${ }^{2,6}$, Antonella Di Sarno 2,7, \\ Maria Lina Tornesello ${ }^{2,8}$, Annamaria Colao ${ }^{2,5}$ and Alessandro Ottaiano ${ }^{1,2}$ \\ 1 Department of Abdominal Oncology, Istituto Nazionale Tumori, IRCCS-Fondazione “G. Pascale”, \\ 80131 Naples, Italy \\ 2 ENETs (European NeuroEndocrine Tumors Society), Center of Excellence of Naples, 80131 Naples, Italy \\ 3 Department of Surgery and Cancer, Imperial College London, London W12 0HS, UK \\ 4 Department of Pathology, Istituto Nazionale Tumori, IRCCS-Fondazione "G. Pascale", 80131 Naples, Italy \\ Department of Clinical Medicine and Surgery, Federico II University, 80131 Naples, Italy \\ UOC of Radiology, Istituto Nazionale Tumori, IRCCS-Fondazione “G. Pascale”, 80131 Naples, Italy \\ 7 UOC of Oncology, A.O. dei Colli, Monaldi Unit, 80131 Naples, Italy \\ 8 Molecular Biology and Viral Oncology Unit, Istituto Nazionale Tumori IRCCS "Fondazione G. Pascale", \\ 80131 Naples, Italy \\ * Correspondence: monicacapozzi@virgilio.it; Tel.: +39-0815-903680 \\ + These authors contributed equally to this work.
}

Received: 11 July 2019; Accepted: 12 August 2019; Published: 15 August 2019

\begin{abstract}
Background. Platinum-based chemotherapy is the mainstay of front-line treatment of patients affected by pluri-metastatic intermediate/high grade NeuroEndocrine Neoplasms (NENs). However, there are no standard second-line treatments at disease progression. Previous clinical experiences have evidenced that temozolomide (TMZ), an oral analog of dacarbazine, is active against NENs at standard doses of 150 to $200 \mathrm{mg} / \mathrm{mq}$ per day on days 1 to 5 of a 28-day cycle, even if a significant treatment-related toxicity is reported. Methods. Metastatic NENs patients were treated at the ENETS (European NeuroEndocrine Tumor Society) center of excellence of Naples (Italy), from 2014 to 2017 with a second-line alternative metronomic schedule of TMZ, $75 \mathrm{mg} / \mathrm{m}^{2}$ per os "one week on/one week off". Toxicity was graded with NCI-CTC criteria v4.0; objective responses with RECIST v1.1 and performance status (PS) according to ECOG. Results. Twenty-six consecutive patients were treated. Median age was 65.5 years. The predominant primary organs were pancreas and lung. Grading was G2 in 11 patients, G3 in 15. More than half of patients had a PS 2 (15 vs. 11 with PS 1). The median time-on-temozolomide therapy was 12.2 months (95\% CI: 11.4-19.6). No G3/G4 toxicities were registered. Complete response was obtained in 1 patient, partial response in 4 , stable disease in 19 (disease control rate: $92.3 \%$ ), and progressive disease in 2 . The median overall survival from TMZ start was 28.3 months. PS improved in $73 \%$ of patients. Conclusions. Metronomic TMZ is a suitable treatment for G2 and G3 NENs particularly in PS 2 patients. Prospective and larger trials are needed to confirm these results.
\end{abstract}

Keywords: neuroendocrine neoplasms; chemotherapy; temozolomide; metronomic treatment; second-line

\section{Introduction}

NeuroEndocrine Neoplasms (NENs) are a group of tumors arising from the neuroendocrine cell compartment present in different tissues [1,2]. Their management is complex and depends 
on tumor grading, differentiation, proliferation index and presence of specific syndromes and/or metastases [3]. The front-line treatment of pluri-metastatic intermediate/high grade NENs is based on systemic platinum-based chemotherapies [4,5]. However, when the disease progresses, there is a lack of evidence for standard second-line treatments.

Temozolomide (TMZ) is an orally active alkylating agent analogue of the dacarbazine. In monotherapy and at the standard doses of $150-200 \mathrm{mg} / \mathrm{m}^{2}$ once daily for 5 every 28 days, TMZ showed to be active in pre-treated patients affected by NENs with response rates (RR) of $14 \%$ in patient with G1/G2 NENs [6] and a disease control rate (DCR) of 38\% in G3 NeuroEndocrine Carcinomas (NECs) [7]. In association with other drugs, namely capecitabine, everolimus, bevacizumab and octreotide, and thalidomide the RR ranges between 17-70\% [8-16]. The large part of these studies is small ( $<25$ patients) and/or retrospective because of the low incidence of the disease. The most frequent reported all-grade toxicities of TMZ single-agent or combined with other drugs are anemia, leucopenia, thrombocytopenia, hand-foot syndrome and gastrointestinal. However, a discontinuation rate of TMZ up to 55\% is reported [16], and in association with everolimus, the treatment with TMZ has been precautionary administrated for a maximum of 6 months in order to reduce toxicity [13].

The use a metronomic schedule of TMZ represents a possible way to reduce toxicity. Metronomic TMZ (mTMZ) consists on lower daily doses with greater frequency of administration. The main biological effects reside on anti-angiogenic activity [17-19] and immune-modulation leading to improvement of dendritic cells function [20] and selective depletion of $\mathrm{CD} 4^{+} \mathrm{CD} 25^{+} \mathrm{Foxp} 3^{+}$regulatory $\mathrm{T}$ cells (Tregs), which are potent immunosuppressive cells within the tumor microenvironment [21-24].

There are no studies in literature evaluating the activity and safety of mTMZ in advanced pre-treated intermediate/high grade NENs. In this study, we evaluated the efficacy of mTMZ in a consecutive series of 26 NENs patients treated at the ENETS (European NeuroEndocrine Tumor Society) center of Naples.

\section{Experimental Section}

\subsection{Patients, Treatment and Disease Characteristics}

This was a retrospective study approved by the Scientific Directorate (among criteria: Reliable and verifiable source of data, consecutiveness of the cases to reduce biases, adequate follow-up, monocentric radiologic evaluations) of the National Cancer Institute of Naples and conducted at the ENETS Center of Excellence in Naples (Italy). The ENETS center of Naples internal database collects data about NENs' patients from three different institutions; it was utilized to identify consecutive cases of patients with advanced G2-G3 NENs (Naples, Italy), progressed after a first-line systemic therapy and treated with second-line mTMZ therapy between 2014 and 2017. All patients had progressive and measurable metastatic disease with an Eastern Cooperative Oncology Group Performance Status (ECOG PS) from 0 to 2 and life expectancy greater than three months. Adequate hematological, renal, and hepatic function with laboratory values demonstrating WBC $\geq 3000 / \mathrm{mm}^{3}$, platelet count $\geq 100,000 / \mathrm{mm}^{3}$, hemoglobin $>8.0 \mathrm{~g} / \mathrm{dL}$, ALT and AST $\leq$ to 3.5 times the upper limit of normal, creatinine $\leq 1.6 \mathrm{mg} / \mathrm{dL}$, and total bilirubin $\leq 2.0 \mathrm{mg} / \mathrm{dL}$ were also required. Patients were excluded in case of active systemic infections, coagulation disorders or decompensated chronic illnesses. Following the procedures of our Institute, retrospective studies are submitted only to the approval of Scientific Directorate and do not require ethical approval.

The treatment schedule consisted on oral administration of "one week on/one week off" TMZ at $75 \mathrm{mg} / \mathrm{m}^{2}$ until unacceptable toxicity or progression. The drug was taken on an empty stomach ( $1 \mathrm{~h}$ before or $2 \mathrm{~h}$ after eating), with a full glass of water. Written informed consent was obtained before prescribing and starting therapy. Data about patients and disease characteristics (age, gender, PS, comorbidities, stage), histology (primary tumor site and size, Ki67 status), previous treatments (surgery and/or systemic treatments) were shown in Table 1. The median age was 65.5 years (range: $32-88$ years) and the genders were equally represented (13 patients were male and 13 patients 
were female). Fifteen patients (58\%) had an ECOG PS of 2 before starting the second line treatment, while 11 patients (42\%) presented with a PS equal to 1 . No patient had a PS of 0 . Grading is a fundamental characteristic to drive therapeutic choices, G2 NENs were $42 \%$ and G3 58\%. Among the G3 NENs, 10 out of $15(67 \%)$ had a Ki67 between $20 \%$ and 55\%. The predominant primary sites were pancreas and lung, whereas the predominant site of metastasis was the liver followed by loco-regional nodes and bone. In half of the patients, metastases were present in a single site, and the liver was the only involved site in the $81 \%$ of patients. In contrast, 8 patients $(31 \%)$ had two different sites of metastasis, and in 5 patients (19\%) the sites of metastasis were equal or more than three. The majority of patients $(54 \%)$ was previously treated with chemotherapy, whereas $31 \%$ received Somato Statin Analogues (SSAs) as first line treatment, and 15\% received other treatments including immunotherapy or targeted/biologic therapies. Of the 14 patients who received first line chemotherapy, 12 received platinum-based treatments and two non-platinum chemotherapy regimens. In addition, among the chemo-treated patients, 10 (71\%) had a G3 NEN but 4 (29\%) had a G2 NEN. In the latter patients, the choice to administer chemotherapy was based on the primary site of the NENs and/or on the Ki67: two atypical carcinoids with a Ki67 $\geq 15 \%$, one intracranial neuroendocrine tumor and one NEN of unknown primary origin with a Ki67 of $18 \%$. Of the 8 patients who received SSAs, half received octreotide and half lanreotide.

Table 1. Characteristics of patients and disease.

\begin{tabular}{|c|c|}
\hline Characteristics & No. \\
\hline \multicolumn{2}{|l|}{ Age, years } \\
\hline Median & 65 \\
\hline Range & $32-88$ \\
\hline \multicolumn{2}{|l|}{ Gender } \\
\hline Male & 13 \\
\hline Female & 13 \\
\hline \multicolumn{2}{|l|}{ Grading } \\
\hline G1 & 0 \\
\hline G2 & 11 \\
\hline $\mathrm{G} 3$ * & 15 \\
\hline \multicolumn{2}{|l|}{ KI-67 level } \\
\hline $3-20$ & 11 \\
\hline $20-55$ & 10 \\
\hline$>55$ & 5 \\
\hline \multicolumn{2}{|l|}{ Performance Status } \\
\hline 0 & 0 \\
\hline 1 & 11 \\
\hline 2 & 15 \\
\hline \multicolumn{2}{|l|}{ Site of primary tumor } \\
\hline Pancreas & 5 \\
\hline Lung & 5 \\
\hline Stomach & 3 \\
\hline \multicolumn{2}{|l|}{ Miscellanea } \\
\hline Head and Neck & 2 \\
\hline Small bowel & 3 \\
\hline Rectum & 1 \\
\hline Gallbladder & 1 \\
\hline Cutaneous & 1 \\
\hline Unknown Primary Origin & 5 \\
\hline \multicolumn{2}{|l|}{ No. of involved metastatic sites } \\
\hline 1 & 13 \\
\hline 2 & 8 \\
\hline$\geq 3$ & 5 \\
\hline \multicolumn{2}{|l|}{ Previous treatments } \\
\hline Platinum-based treatments & 12 \\
\hline $\begin{array}{l}\text { Chemotherapy non-platinum } \\
\text { based }\end{array}$ & 2 \\
\hline Somatostatin analogues & 8 \\
\hline Clinical trials drugs & 4 \\
\hline
\end{tabular}

* 3 Large Cell NECs were included, small-cell types were not included. 


\subsection{Activity, Toxicity and Clinical Benefit Evaluations}

Tumor assessment was performed every three months through Computed Tomography (CT) scans. Responses to treatment were defined according to RECIST 1.1 (Response Evaluation Criteria in Solid Tumors) [20]. Complete response (CR) was defined as the disappearance of all lesions, and partial response (PR) as a decrease of $30 \%$ or more in the sum of the longest diameters. Progressive disease (PD) was defined as either the appearance of new lesions or an increase of $20 \%$ or more compared with the minimum sum of longest diameters recorded since the start of treatment. Stable disease (SD) was defined when the sum increased by $<20 \%$ or decreased by $<30 \%$ and no new lesions appeared. The objective response rate (ORR) was the sum of CRs + PRs. The disease control rate (DCR) was the sum of CRs + PRs + SDs.

Adverse events were graded according to the National Cancer Institute Common Terminology Criteria for Adverse Events (NCI-CTCAE version 4) [25]. Physical examination, complete blood counts and blood chemical tests were carried out once a week until the end of the second month and once every 2 weeks thereafter. For each adverse event, the maximum grade per patient was reported. If a patient experienced a toxic effect of any grade on multiple occasions, the event was counted only once. Patients' toxicities attributable to prior first-line treatment must have recovered to a grade 1 or less (except for alopecia) before starting mTMZ. No grade 3 or 4 toxicities were observed. Grade 2 non-hematologic toxicities were managed by cessation of the drug until resolution to grade 1 and then resuming treatment without a dose reduction. Neither treatment delays nor reductions were applied in case of hematologic grade 1 or 2 or non-hematologic grade 1 toxicities.

The clinical benefit was defined as an improvement of the ECOG PS assessed before starting mTMZ, at 3 and 6 months.

\subsection{Time-to-Outcome Analysis and Statistical Methods}

Data are predominantly descriptive. Progression free survival (PFS) was calculated as the time elapsed from the date of $\mathrm{mTMZ}$ initiation to the date of disease progression or death for any cause (whichever occurred first). Patients who were alive with no disease progression were censored at the date of last visit. Overall Survival (OS) was defined as the time from the start of mTMZ administration to the date of death for any cause. Patients who were alive were censored at the date of data analysis. The median PFS (mPFS) and the median OS (mOS) curves were depicted using the Kaplan-Meier method. Exploratory subgroup analyses were done by Log-rank test.

\section{Results}

\section{Efficacy and Safety}

From 2014 to 2017, twenty-six consecutive patients with advanced G2-G3 NENs in progression after a first line chemotherapy were treated with second-line mTMZ. Characteristics of patients and their disease have been described in the Experimental Section. At last follow-up (median follow-up from mTMZ start: 29 months), 16 (62\%) patients were alive, and 8 (31\%) were still on treatment with mTMZ. All patients were evaluable for response. The objective response rate (ORR) to second-line mTMZ was 19\%, with one complete response (CR) and four partial responses (PR). An additional 73\% of patients achieved stable disease (SD) as best response (Table 2 and Figure 1a).

Table 2. Efficacy estimates of second-line mTMZ.

\begin{tabular}{ll}
\hline \multicolumn{1}{c}{ Response to Therapy } & No. (\%) \\
\hline Complete Response & $1(3.8)$ \\
Partial Response & $4(15.4)$ \\
Stable Disease & $19(73.1)$ \\
Progressive Disease & $2(7.6)$ \\
Median PFS (18 events) & 9.0 months \\
Median OS (10 events) & 28.3 months \\
\hline
\end{tabular}


a)

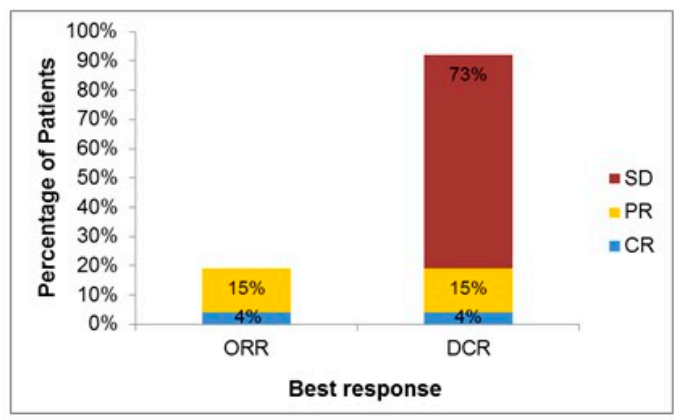

b)

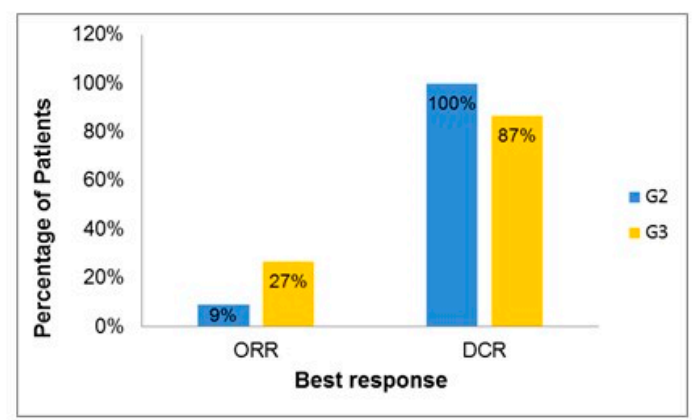

c)

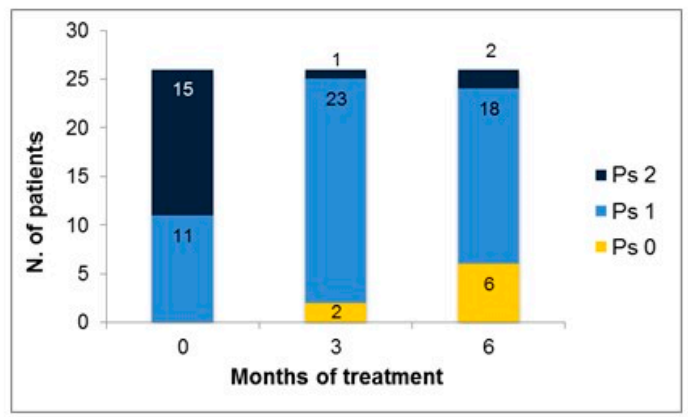

Figure 1. Histogram representations of activity and clinical benefit of mTMZ. Response rates with mTMZ in all patients (a) and according to grading (G2 vs. G3) of the tumor (b). Improvement of ECOG PS over 3 and 6 months of treatment (c). CR = Complete Response; DCR = Disease Control Rate; ORR = Overall Response Rate; PR = Partial Response; PS = Performance Status; SD = Stable Disease.

The overall DCR was 92\%. The ORR and DCR in patients with G2 NENs were 9\% and 100\%, respectively, while for those with G3 NENs the ORR was 27\% and the DCR was 87\% (Figure 1b). A clinical improvement of the basal PS was reported in $73 \%$ of patients (Figure 1c). The mPFS was 9 months and longer for patients with G2 NENs (mPFS: 23.6 months) compared to patients with G3 NENs (mPFS: 8.9 months), although not significant $(p=0.16)$ (Figure 2).

$\mathrm{A}$

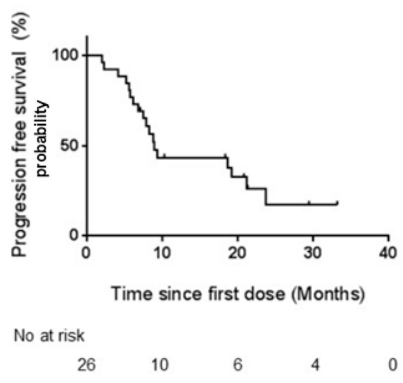

C

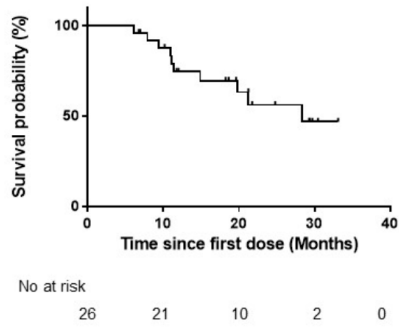

B

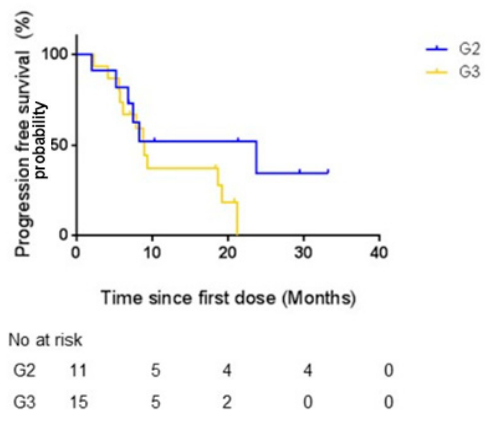

D

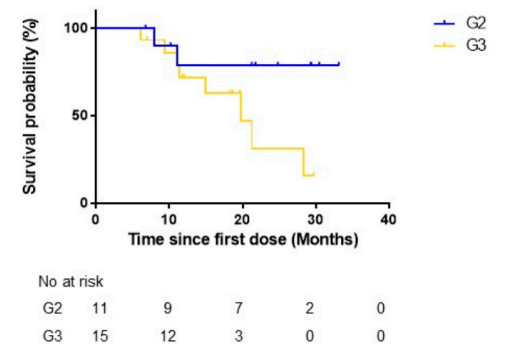

Figure 2. Time-to-outcome analyses. Curves of progression-free survival and overall survival in all patients $(\mathbf{A}, \mathbf{C})$ and according to grading $(\mathbf{B}, \mathbf{D})$. 
The mOS was 28.3 months in the entire population. The mOS was 19.8 months in patients with G3 NENs and not reached in patient with G2 NENs $(p=0.60)$ (Figure 2). No G3/G4 toxicities were registered (Table 3); no dose reductions were reported. The two most common adverse events were anemia and asthenia (Table 3). The median time-on-TMZ therapy was 12.2 months (95\% CI: 11.4-19.6). No patient discontinued treatment for the occurrence of severe adverse events.

Table 3. Summary of adverse events.

\begin{tabular}{lllllll}
\hline \multirow{2}{*}{ Toxicity } & G1 & \multicolumn{3}{c}{ G2 } & \multicolumn{3}{c}{ G3/G4 } \\
\cline { 2 - 7 } & No & \% & No & \% & No & $\%$ \\
\hline Anaemia & 11 & 42.3 & 13 & 50.0 & 0 & 0.0 \\
Asthenia & 9 & 34.6 & 12 & 46.1 & 0 & 0.0 \\
Neuropathy & 8 & 30.7 & 10 & 38.4 & 0 & 0.0 \\
Neutropenia & 8 & 30.7 & 8 & 30.7 & 0 & 0.0 \\
Nausea & 7 & 26.9 & 8 & 30.7 & 0 & 0.0 \\
Hyperbilirubinemia & 7 & 26.9 & 6 & 23.1 & 0 & 0.0 \\
Alkaline phosphatase & 3 & 11.5 & 0 & 0.0 & 0 & 0.0 \\
Hyperglycaemia & 4 & 15.3 & 6 & 23.1 & 0 & 0.0 \\
Thrombocytopenia & 0 & 0.0 & 6 & 23.1 & 0 & 0.0 \\
\hline
\end{tabular}

\section{Discussion}

Currently, the optimal schedule for TMZ has still not been established. Different schedules have been used in recent trials both in monotherapy and in association with other drugs [6-16]; these studies were heterogeneous in terms of sample size, histology, grading, and number and type of previous treatments (Table S1 in Supplementary Material). Although a significant activity was constantly reported with these schedules, the median time on TMZ was negatively influenced by G3/G4 toxicities $[6,13,16]$ with a discontinuation rate up to $55 \%$. This highlights the need to minimize toxicity. To this regard, albeit retrospective and exploratory, we report the first "hypothesis generating" study with mTMZ 75mg/m² "one week on-one week off" scheme in NENs. The treatment was associated with an ORR of $19 \%$ and an overall DCR of $92 \%$; most importantly, no G3/G4 adverse events and no interruptions of treatment for toxicity were registered. In addition, $\mathrm{mTMZ}$ determined a clinical benefit through improvement of PS.

Notably, there were no significant relationships between response to therapy and characteristics of patients and disease, including age ( $\leq 65$ vs. $>65$ years), sex (male vs. female), PS ECOG ( 1 vs. 2 ), site of primary tumor [gastro-intestinal (GI) vs. no-GI], KI-67 level ( $<20$ vs. $\geq 20 \%$ ), grading (G2 vs. G3), number of metastatic sites ( 1 vs. 2 vs. $\geq 3$ ) and previous treatments (see Table S2 in Supplementary Material). However, we cannot rule out the hypothesis that such evaluations could be affected by the small sample size of our series. In fact, although not significant, responses were more frequently observed in G3 NENs (4 pts) compared to G2 (1 patient). It is well known that grade is associated with cell proliferation rate which is a consistent indicator of chemosensitivity. Unfortunately, high grade tumors are in turn characterized by high genomic heterogeneity with frequent p53, Hedgehog and Notch mutations [26] (associated to drug resistance and plasticity of stem-like states), and after an initial response to therapy, they acquire a drug resistant phenotype in a short time. For this reason, very frequently, a discrepancy is observed between higher response rates and shorter progression-free survival in G3 NENs, as occurs in our series.

The clinical advantages of a low-dose administration of TMZ have been explored over the last 20 years and are mainly based on (i) a lower toxicity profile eventually associated (ii) to a better quality of life [27-30]. An important characteristic of our series was the inclusion of 15 pts with PS ECOG $2(57.7 \%)$ while in previous trials it ranged from 0 to $28 \%$ (Table S1 in Supplementary Material). Interestingly, mTMZ was well-tolerated, without any G3/G4 adverse effects, and in 14 out of 15 pts there was an improvement of PS 2 to PS 1 after 3 months of therapy. This suggests that mTMZ might 
be given to patients with deteriorated PS when the benefit-risk balance is not favorable for more aggressive treatments.

Furthermore, beyond these clinical advantages, mTMZ, but not the conventional scheme, is able to trigger anti-angiogenetic and immune-mediated pathways [17-23]. NENs are hypervascularised tumors and overexpress a plethora of proangiogenic molecules and related receptors [31-35]. Therefore, given their high dependence from angiogenic pathways, the metronomic schedule, through its predominant anti-angiogenic action, could represent a stronger candidate for NENs treatment. Additionally, metronomic therapy exerts its anti-angiogenetic activity through the increase of the inhibitor thrombospodin-1 (THBS-1) and the inhibition of the hypoxia-inducible factor 1 (HIF-1) [36]. These biologic properties account for a more potent and clinically relevant anti-angiogenic than cytotoxic effect of mTMZ. Furthermore, these latter effects could be particularly interesting for combination with mTOR inhibitors (i.e., everolimus). Inhibition of mTORC1 (mTOR Complex 1) causes the loss of a negative feedback loop that activates HIF-1 [37]; therefore, the association of an mTOR inhibitor with mTMZ might preserve the anti-angiogenic activity of this loop.

Notably, the evaluation of O6-methylguanine DNA methyltransferase (MGMT), which repairs the methylation at the O6-position of guanine induced by alkylating agents [38-41] did not show to be significant in our series. Our group is going to accumulate more data about this issue. On the basis of these clinical results and to further investigate the role of $\mathrm{mTMZ}$ in second-line treatment of G3 NENs, a study is currently ongoing at the ENETS center of Naples. This larger and prospective clinical trial named TENEC trial (TEmozolomide in NeuroEndocrine Carcinoma), is supported by ITANET (ITalian Association for NEuroendocrine Tumors) and aims to confirm the efficacy and toxicity results of mTMZ as well as its modulating effects on host' immune system.

Despite the exploratory and retrospective nature of our study, the efficacy of mTMZ in monotherapy here reported is similar to that shown in other retrospective trials with conventional schedules of TMZ monotherapy; conversely, the toxicity profile is clearly better.

\section{Conclusions}

Our study is a proof of concept that an intermittent schedule of mTMZ at $75 \mathrm{mg} / \mathrm{m}^{2}$ can be an effective treatment in advanced G2-3 NENs, a suitable therapeutic option for PS 2 patients as well as a strong candidate also for combination treatments.

Supplementary Materials: The following are available online at http://www.mdpi.com/2077-0383/8/8/1224/s1, Table S1: Characteristics of studies reporting outcomes of TMZ in NENs, Table S2: Clinico-pathological characteristics of patients according to treatment response.

Author Contributions: Conceptualization, A.O., C.v.A., S.T., A.C.; methodology, A.O. and M.C.; validation, C.v.A., M.C., M.M., F.T., S.T.; formal analysis, A.O., M.C. and C.v.A.; investigation, A.C., S.T., C.v.A., M.C., R.M., M.M., F.T., M.L.B., M.L.T., A.D.S.; data curation, C.v.A. and A.C.; writing and original draft preparation, A.O., M.C., S.T., C.v.A.

Funding: This research was funded by Lega Italiana per la Lotta contro i Tumori (LILT), Naples section.

Acknowledgments: We thank Alessandra Trocino, Librarian at the Library of Istituto Nazionale Tumori Fondazione 'G Pascale', Naples, Italy, for her excellent bibliographic service and assistance.

Conflicts of Interest: The authors declare no conflict of interest.

\section{References}

1. Dasari, A.; Shen, C.; Halperin, D.; Zhao, B.; Zhou, S.; Xu, Y.; Shih, T.; Yao, J.C. Trends in the Incidence, Prevalence, and Survival Outcomes in Patients with Neuroendocrine Tumors in the United States. JAMA Oncol. 2017, 3, 1335-1342. [CrossRef] [PubMed]

2. National Comprehensive Cancer Network. Neuroendocrine and Adrenal Tumor (Version 2.2018). Available online: https://www.nccn.org/professionals/physician_gls/PDF/neuroendocrine.pdf (accessed on 2 August 2019). 
3. Hallet, J.; Law, C.H.; Cukier, M.; Saskin, R.; Liu, N.; Singh, S. Exploring the rising incidence of neuroendocrine tumors: A population-based analysis of epidemiology, metastatic presentation, and outcomes. Cancer 2015, 121, 589-597. [CrossRef] [PubMed]

4. Pavel, M.; Costa, F.; Capdevila, J.; Gross, D.; Kianmanesh, R.; Krenning, E.; Knigge, U.; Salazar, R.; Pape, U.F.; Öberg, K. ENETS Consensus Guidelines Update for the Management of Distant Metastatic Disease of Intestinal, Pancreatic, Bronchial Neuroendocrine Neoplasms (NEN) and NEN of Unknown Primary Site. Neuroendocrinology 2016, 103, 172-185. [CrossRef] [PubMed]

5. Strosberg, J.R.; Halfdanarson, T.R.; Bellizzi, A.M.; Chan, J.A.; Dillon, J.S.; Heaney, A.P.; Kunz, P.L.; O'Dorisio, T.M.; Salem, R.; Segelov, E.; et al. The North American Neuroendocrine Tumor Society Consensus Guidelines for Surveillance and Medical Management of Midgut Neuroendocrine Tumors. Pancreas 2017, 46, 707-714. [CrossRef] [PubMed]

6. Ekeblad, S.; Sundin, A.; Janson, E.T.; Welin, S.; Granberg, D.; Kindmark, H.; Dunder, K.; Kozlovacki, G.; Örlefors, H.; Sigurd, M.; et al. Temozolomide as monotherapy is effective in treatment of advanced malignant neuroendocrine tumors. Clin. Cancer Res. 2007, 13, 2986-2991. [CrossRef] [PubMed]

7. Olsen, I.H.; Sørensen, J.B.; Federspiel, B.; Kjaer, A.; Hansen, C.P.; Knigge, U.; Langer, S.W. Temozolomide as second or third line treatment of patients with neuroendocrine carcinomas. Sci. World J. 2012, 2012, 170496. [CrossRef] [PubMed]

8. Strosberg, J.R.; Fine, R.L.; Choi, J.; Nasir, A.; Coppola, D.; Chen, D.T.; Helm, J.; Kvols, L. First-line chemotherapy with capecitabine and temozolomide in patients with metastatic pancreatic endocrine carcinomas. Cancer 2011, 117, 268-275. [CrossRef]

9. Welin, S.; Sorbye, H.; Sebjornsen, S.; Knappskog, S.; Busch, C.; Öberg, K. Clinical effect of temozolomide-based chemotherapy in poorly differentiated endocrine carcinoma after progression on first-line chemotherapy. Cancer 2011, 117, 4617-4622. [CrossRef]

10. Saif, M.W.; Kaley, K.; Brennan, M.; Garcon, M.C.; Rodriguez, G.; Rodriguez, T. A retrospective study of capecitabine/temozolomide (CAPTEM) regimen in the treatment of metastatic pancreatic neuroendocrine tumors (pNETs) after failing previous therapy. JOP 2013, 14, 498-501.

11. Fine, R.L.; Gulati, A.P.; Krantz, B.A.; Moss, R.A.; Schreibman, S.; Tsushima, D.A.; Mowatt, K.B.; Dinnen, R.D.; Mao, Y.; Stevens, P.D.; et al. Capecitabine and temozolomide (CAPTEM) for metastatic, well-differentiated neuroendocrine cancers: The Pancreas Center at Columbia University experience. Cancer Chemother. Pharmacol. 2013, 71, 663-670. [CrossRef]

12. Saranga-Perry, V.; Morse, B.; Centeno, B.; Kvols, L.; Strosberg, J. Treatment of metastatic neuroendocrine tumors of the thymus with capecitabine and temozolomide: A case series. Neuroendocrinology 2013, 97, 318-321. [CrossRef] [PubMed]

13. Chan, J.A.; Blaszkowsky, L.; Stuart, K.; Zhu, A.X.; Allen, J.; Wadlow, R.; Ryan, D.P.; Meyerhardt, J.; Gonzalez, M.; Regan, E.; et al. A prospective, phase 1/2 study of everolimus and temozolomide in patients with advanced pancreatic neuroendocrine tumor. Cancer 2013, 119, 3212-3218. [CrossRef] [PubMed]

14. Koumarianou, A.; Antoniou, S.; Kanakis, G.; Economopoulos, N.; Rontogianni, D.; Ntavatzikos, A.; Tsavaris, N.; Pectasides, D.; Dimitriadis, G.; Kaltsas, G. Combination treatment with metronomic temozolomide, bevacizumab and long-acting octreotide for malignant neuroendocrine tumors. Endocr. Relat. Cancer 2012, 19, L1-L4. [CrossRef] [PubMed]

15. Chan, J.A.; Stuart, K.; Earle, C.C.; Clark, J.W.; Bhargava, P.; Miksad, R.; Blaszkowsky, L.; Enzinger, P.C.; Meyerhardt, J.A.; Zheng, H.; et al. Prospective study of bevacizumab plus temozolomide in patients with advanced neuroendocrine tumors. J. Clin. Oncol. 2012, 30, 2963-2968. [CrossRef] [PubMed]

16. Kulke, M.H.; Stuart, K.; Enzinger, P.C.; Ryan, D.P.; Clark, J.W.; Muzikansky, A.; Vincitore, M.; Michelini, A.; Fuchs, C.S. Phase II study of temozolomide and thalidomide in patients with metastatic neuroendocrine tumors. J. Clin. Oncol. 2006, 24, 401-406. [CrossRef] [PubMed]

17. Kurzen, H.; Schmitt, S.; Näher, H.; Möhler, T. Inhibition of angiogenesis by non-toxic doses of temozolomide. Anticancer Drugs 2003, 14, 515-522. [CrossRef] [PubMed]

18. Sun, C.; Yu, Y.; Wang, L.; Wu, B.; Xia, L.; Feng, F.; Ling, Z.; Wang, S. Additive antiangiogenesis effect of ginsenoside Rg3 with low-dose metronomic temozolomide on rat glioma cells both in vivo and in vitro. $J$. Exp. Clin. Cancer Res. 2016, 35, 32. [CrossRef] [PubMed] 
19. Woo, J.Y.; Yang, S.H.; Lee, Y.S.; Lee, S.Y.; Kim, J.; Hong, Y.K. Continuous Low-Dose Temozolomide Chemotherapy and Microvessel Density in Recurrent Glioblastoma. J. Korean Neurosurg. Soc. 2015, 58, 426-431. [CrossRef]

20. Kaneno, R.; Shurin, G.V.; Tourkova, I.L.; Shurin, M.R. Chemomodulation of human dendritic cell function by antineoplastic agents in low noncytotoxic concentrations. J. Transl. Med. 2009, 7, 58. [CrossRef]

21. Ghiringhelli, F.; Menard, C.; Puig, P.E.; Ladoire, S.; Roux, S.; Martin, F.; Solary, E.; Le Cesne, A.; Zitvogel, L.; Chauffert, B. Metronomic cyclophosphamide regimen selectively depletes $\mathrm{CD} 4{ }^{+} \mathrm{CD} 25^{+}$regulatory T cells and restores $\mathrm{T}$ and NK effector functions in end stage cancer patients. Cancer Immunol. Immunother. 2007, 56, 641-648. [CrossRef]

22. Banissi, C.; Ghiringhelli, F.; Chen, L.; Carpentier, A.F. Treg depletion with a lowdose metronomic temozolomide regimen in a rat glioma model. Cancer Immunol. Immunother. 2009, 58, 1627-1634. [CrossRef] [PubMed]

23. Zhao, J.; Cao, Y.; Lei, Z.; Yang, Z.; Zhang, B.; Huang, B. Selective depletion of CD4 ${ }^{+} \mathrm{CD} 25^{+}$Foxp3 ${ }^{+}$regulatory T cells by low-dose cyclophosphamide is explained by reduced intracellular ATP levels. Cancer Res. 2010, 70, 4850-4858. [CrossRef] [PubMed]

24. Kan, S.; Hazama, S.; Maeda, K.; Inoue, Y.; Homma, S.; Koido, S.; Okamoto, M.; Oka, M. Suppressive Effects of Cyclophosphamide and Gemcitabine on Regulatory T-Cell Induction In Vitro. Anticancer Res. 2012, 32, 5363-5369. [PubMed]

25. National Institute of Health. Available online: https://ctep.cancer.gov/protocolDevelopment/electronic applications/ctc.htm\#ctc_40 (accessed on 2 August 2019).

26. Girardi, D.M.; Silva, A.C.B.; Rêgo, J.F.M.; Coudry, R.A.; Riechelmann, R.P. Unraveling molecular pathways of poorly differentiated neuroendocrine carcinomas of the gastroenteropancreatic system: A systematic review. Cancer Treat. Rev. 2017, 56, 28-35. [CrossRef] [PubMed]

27. Fidler, I.J.; Ellis, L.M. Chemotherapeutic drugs-More really is not better. Nat. Med. 2000, 6, 500-502. [CrossRef]

28. Gatenby, R.A.; Silva, A.S.; Gillies, R.J.; Frieden, B.R. Adaptive Therapy. Cancer Res. 2009, 69, 4894-4903. [CrossRef]

29. Scharovsky, O.G.; Mainetti, L.E.; Rozados, V.R. Metronomic chemotherapy: Changing the paradigm that more is better. Curr. Oncol. 2009, 16, 7-15. [CrossRef]

30. Pasquier, E.; Kavallaris, M.; André, N. Metronomic chemotherapy: New rationale for new directions. Nat. Rev. Clin. Oncol. 2010, 7, 455-465. [CrossRef]

31. Scoazec, J.Y. Angiogenesis in neuroendocrine tumors: Therapeutic applications. Neuroendocrinology 2013, 97, 45-56. [CrossRef]

32. Besig, S.; Voland, P.; Baur, D.M.; Perren, A.; Prinz, C. Vascular endothelial growth factors, angiogenesis, and survival in human ileal enterochromaffin cell carcinoids. Neuroendocrinology 2009, 90, 402-415. [CrossRef]

33. Zhang, J.; Jia, Z.; Li, Q.; Wang, L.; Rashid, A.; Zhu, Z.; Evans, D.B.; Vauthey, J.N.; Xie, K.; Yao, J.C. Elevated expression of vascular endothelial growth factor correlates with increased angiogenesis and decreased progression-free survival among patients with low-grade neuroendocrine tumors. Cancer 2007, 109, 1478-1486. [CrossRef] [PubMed]

34. Zhou, Q.; Guo, P.; Wang, X.; Nuthalapati, S.; Gallo, J.M. Preclinical pharmacokinetic and pharmacodynamic evaluation of metronomic and conventional temozolomide dosing regimens. J. Pharmacol. Exp. Ther. 2007, 321, 265-275. [CrossRef] [PubMed]

35. Lambrescu, I.; Fica, S.; Martins, D.; Spada, F.; Cella, C.; Bertani, E.; Rubino, M.; Gibelli, B.; Grana, C.; Bonomo, G.; et al. Metronomic and metronomic-like therapies in neuroendocrine tumors-Rationale and clinical perspectives. Cancer Treat. Rev. 2017, 55, 46-56. [CrossRef] [PubMed]

36. André, N.; Carré, M.; Pasquier, E. Metronomics: Towards personalized chemotherapy? Nat. Rev. Clin. Oncol. 2014, 11, 413-431. [CrossRef] [PubMed]

37. Figlin, R.A.; Kaufmann, I.; Brechbiel, J. Targeting PI3K and mTORC2 in metastatic renal cell carcinoma: New strategies for overcoming resistance to VEGFR and mTORC1 inhibitors. Int. J. Cancer 2013, 133, 788-796. [CrossRef] [PubMed]

38. Schmitt, A.M.; Pavel, M.; Rudolph, T.; Dawson, H.; Blank, A.; Komminoth, P.; Vassella, E.; Perren, A. Prognostic and predictive roles of MGMT protein expression and promoter methylation in sporadic pancreatic neuroendocrine neoplasms. Neuroendocrinology 2014, 100, 35-44. [CrossRef] [PubMed] 
39. Walter, T.; van Brakel, B.; Vercherat, C.; Hervieu, V.; Forestier, J.; Chayvialle, J.A. O6-Methylguanine-DNA methyltransferase status in neuroendocrine tumors: Prognostic relevance and association with response to alkylating agents. Br. J. Cancer 2015, 112, 523-531. [CrossRef]

40. Kulke, M.H.; Hornick, J.L.; Frauenhoffer, C.; Hooshmand, S.; Ryan, D.P.; Enzinger, P.C.; Meyerhardt, J.A.; Clark, J.W.; Stuart, K.; Fuchs, C.S.; et al. O6-methylguanine DNA methyltransferase deficiency and response to temozolomide-based therapy in patients with neuroendocrine tumors. Clin. Cancer Res. 2009, 15, 338-345. [CrossRef]

41. Raj, N.; Klimstra, D.S.; Horvat, N.; Zhang, L.; Chou, J.F.; Capanu, M.; Basturk, O.; Do, R.K.G.; Allen, P.J.; Reidy-Lagunes, D. O6-Methylguanine DNA Methyltransferase Status Does Not Predict Response or Resistance to Alkylating Agents in Well-Differentiated Pancreatic Neuroendocrine Tumors. Pancreas 2017, 46, 758-763. [CrossRef]

(C) 2019 by the authors. Licensee MDPI, Basel, Switzerland. This article is an open access article distributed under the terms and conditions of the Creative Commons Attribution (CC BY) license (http://creativecommons.org/licenses/by/4.0/). 